\title{
Paradoxos da Proteção Jurídica da Saúde ${ }^{(*)}$
}

\author{
PARADOX OF HEALTH LAW PROTECTION
}

Laurindo Dias Minhoto ${ }^{(*)}$

\section{RESUMO}

O presente artigo analisa o caráter democrático da Constituição Federal de 1988, marcado pela construção de um Estado de bem-estar social, no qual, a saúde foi elevada à categoria de direito social, ganhando contornos abrangentes e progressistas, de acordo com o padrão normativo internacional. O trabalho apresenta os fundamentos e princípios norteadores da política sanitária brasileira, estabelecidos na Constituição de 1988, e avalia o papel do Sistema Único de Saúde, como mecanismo responsável por garantir o direito à saúde para toda a população. $O$ artigo debate o descompasso que existe hoje entre o sentido social que o ordenamento jurídico constitucional conferiu à política de saúde e o desafio de implementar um sistema de proteção à saúde, dentro de um contexto de globalização da economia capitalista.

\section{Palavras-chave}

Direito à Saúde; Democracia; Estado de Bem-Estar Social; Globalização; Ordenamento Jurídico.

\section{ABSTRACT}

This article examines the democratic character of the 1988 Federal Constitution, marked by the construction of a welfare State in which health

${ }^{*}$ ) Artigo baseado em apresentação realizada durante o VII Seminário Internacional de Direito Sanitário, São Paulo, 13 a 15 de setembro de 2006. Recebido em 2.2.7. Aprovado em 12.7.7.

${ }^{* *}$ Professor de Sociologia Jurídica da Escola de Direito de São Paulo da Fundação Getúlio Vargas, professor visitante da Faculdade de Saúde Pública da Universidade de São Paulo e membro do Conselho Editorial de Social \& Legal Studies. E-mail: <ldm @usp.br> 
was elevated to the category of social right, with progressive contours, according to the international standard rules. This work presents the guidelines of the Brazilian health policy, established in the Constitution of 1988, and the role of the Sistema Único de Saúde as a mechanism responsible for the guarantee of the right to health for the entire population. This article also discuss the gap between the social sense given for the constitutional law to health policy and the challenge of implementing a system of health protection, in a context of globalization.

\section{Key words}

Democracy; Globalization; Law Order; Right to Health; Welfare State.

\section{INTRODUÇÃO}

Em nossa peculiar terra do nunca, em que os diferentes momentos do processo histórico de modernização tendem a se truncar antes mesmo de a realidade poder conferir um mínimo de plausibilidade empírica a suas promessas, o acerto involuntário que a ignorância crassa de uma bizarra liderança partidária pôs em prática recentemente - ao ressignificar o caminho trilhado pela desajustada tradição iluminista no país, chamando-a por um de seus possíveis nomes próprios - o ilusionismo - de certo modo mira o alvo da crítica de forma mais precisa do que fariam supor as vãs esperanças de desqualificação sistemática da parte de setores bem-pensantes de nossa sociedade.

Com efeito, como não identificar a marca do ilusionismo no andamento da modernização do país que, conforme sublinha a melhor tradição do chamado pensamento social brasileiro, ao que parece mais atual do que nunca neste ponto decisivo, se moderniza pela reposição das forças do atraso e tem mudado para permanecer, em essência, igual a si próprio?

Ainda que em patamares de crescente complexidade, dados pela dinâmica de superposição de distintos ciclos históricos, como não divisar na viagem redonda da modernização nacional as marcas do baixo profundo que ressoam

1. na indistinção entre esfera pública e esfera privada;

2. na privatização do público;

3. na corrupção sistêmica;

4. no tratamento policial da crise social;

5. na violência intersubjetiva, cujo código do sertão ainda funciona como paradigma da sociabilidade; 
6. na lógica segregacionista do espaço urbano, marcada pela proliferação de estratégias neohigienistas;

7. na democracia como mal-entendido e, last but not least, e

8. no caráter lábil e arbitrário do direito, soçobrando entre os pólos da inefetividade e da ausência da lei, de resto, traço constituinte de nossa dialética da ordem e da desordem?

Existem alguns paradoxos subjacentes ao que talvez se pudesse supor como mais um capítulo da marcha desajustada e truncada da modernização do país, ou seja, ao seu modo peculiar, e vistas as coisas em retrospecto, um notável capítulo, bastante recente, do ilusionismo iluminista nacional, a saber, o da social-democracia como mal-entendido, ou seja, a construção jurídica de um Estado de bem-estar brasileiro, cujo marco normativo se organiza, como se sabe, a partir da promulgação da Constituição Federal de 1988 e que tem na política de saúde uma de suas vertentes centrais.

Neste passo, não custa lembrar que, tanto aqui que como alhures, a fantasmagoria tem base no real.

$\mathrm{Na}$ esteira do processo de redemocratização, de crescente participação da sociedade civil e de reforma sanitária, o texto constitucional de 1988 não se limita a organizar juridicamente o poder, nem a arrolar os direitos civis, políticos e sociais do cidadão, assegurando o espaço da liberdade individual; ele vai muito além disso, ao estipular os objetivos, princípios e agentes com base nos quais o Estado deve formular e executar políticas públicas e, portanto, prescreve-Ihe obrigações positivas. Nessa medida, como apontam inúmeros juristas, trata-se de uma Constituição Dirigente, que adota a forma jurídico-política do Estado do Bem-Estar Social.

A Constituição elevou a saúde à categoria de direito social (art. 6º), estabeleceu os fundamentos e fixou os princípios norteadores da política sanitária brasileira, desenhou o marco institucional encarregado de executar essa política na forma do Sistema Único de Saúde e incorporou uma definição de saúde abrangente e progressista, em sintonia com o padrão normativo internacional (arts. 196 e seguintes).

Pela sistemática constitucional, a saúde se insere no âmbito da seguridade social, que engloba ainda os direitos relativos à previdência e à assistência social (art. 194). A Constituição conceitua saúde como "direito de todos e dever do Estado, garantido mediante políticas sociais e econômicas que visem à redução do risco de doença e de outros agravos e ao acesso universal e igualitário às ações e serviços para sua promoção, proteção e recuperação" (art. 196); declara de relevância pública as ações e serviços de saúde, cabendo ao Poder Público dispor, nos termos da lei, sobre sua regulamentação, fiscalização e controle (art. 197) e institui o Sistema Único de Saúde (SUS) fixando as suas diretrizes em termos de descentralização, atendimento integral, com prioridade para as atividades preventivas e participação da comunidade. 
$\mathrm{Na}$ interpretação da Constituição e do sistema de proteção à saúde devem se levar em conta ainda alguns dos princípios gerais contemplados na Carta de 1988 e que se revestem de inequívoco sentido social: a erradicação da pobreza e da marginalização e a redução das desigualdades sociais e regionais, bem como a promoção do bem de todos, sem preconceitos de origem, raça, sexo, cor, idade e quaisquer outras formas de discriminação (art. 3o, III e IV); a prevalência dos direito humanos como princípio que rege as relações internacionais do Brasil (art.4‥, II); o primado do trabalho e os objetivos do bem-estar e da justiça sociais como fundamento da ordem social (art. 193).

Apresentam-se, portanto, como pontos cardeais do marco jurídico constitucional, que serão replicados em maior ou menor medida na legislação sanitária infraconstitucional,

1. a concepção abrangente de saúde, com ênfase nas noções de risco e de prevenção;

2. o vínculo entre o direito à saúde e o princípio da justiça como igualdade, prevendo o acesso universal aos serviços;

3. e a instituição do SUS em consonância com os ditames do princípio democrático, na medida em que assegura expressamente a participação da comunidade no Sistema.

\section{DIREITO SOCIAL}

Qual é exatamente a materialidade histórica que se sedimenta nessa configuração jurídica da saúde como um direito social?

Os chamados direitos sociais nascem em contexto definido. Num longo processo histórico, que se inicia na segunda metade do século XIX e se consolida após a 2a Grande Guerra, o modelo do Estado Social assinala, a um tempo, o fim do capitalismo concorrencial e a integração parcial das classes trabalhadoras no quadro político-institucional das sociedades industrializadas do Ocidente.

Mais especificamente, dois fatores decisivos contribuíram para a "repolitização" relativa das relações sociais naquela quadra histórica: a concentração dos mercados e a coletivização dos conflitos sociais, fatores que irão operar um abalo significativo no mito da externalidade do Estado burguês.

No que diz respeito ao processo de acumulação capitalista, o Estado é chamado a agregar novas funções às que tradicionalmente desempenhava na ordem liberal, entre as quais, avultam a do planejamento da economia e a da formulação de políticas sociais.

O Estado desempenha as suas novas funções num campo de forças potencialmente contraditório. De um lado, trata-se de assegurar as condições 
necessárias à garantia da reprodução do processo de acumulação do capital, basicamente pela regulação econômica; de outro, trata-se de neutralizar o potencial explosivo dos conflitos gerados pela dinâmica desse mesmo processo acumulativo, fundamentalmente, pela instituição de uma rede de proteção social.

O caráter regulador dos Estados de bem-estar assume aqui o sentido preciso de controle das forças de mercado, seja pela arbitragem pública da concorrência intercapitalista, seja pela juridificação da questão social.

Forjado no contexto das lutas de classe que viabilizou os grandes pactos sociais-democratas entre capital e trabalho, e desenvolvido no âmbito das Constituições Dirigentes dos Estados de bem-estar, o conceito de direito social pressupõe historicamente um aparato regulatório capaz de impor políticas sociais pela via de mecanismos tributários com sentido redistributivista, implicando um tratamento eminentemente coletivo para a questão dos riscos sociais. Nos termos de uma formulação bastante conhecida, de François Ewald,

"o direito social visa a se constituir como um instrumento de intervenção que procura compensar e corrigir situações de desigualdade e restaurar equilíbrios ameaçados. $O$ direito social é um direito de preferências, um direito de não reciprocidade, um direito de discriminações positivas." (Ewald, 1988:46)

Em termos estritamente jurídicos, o novo direito visa a superar a velha concepção liberal de contrato, expressa no ideal de justiça comutativa derivado da suposta equivalência dos termos das trocas que ocorrem no mercado, por uma nova concepção de contrato, baseada no ideal da solidariedade. E o que pode significar exatamente a passagem do contrato típico de direito civil para o novo contrato de solidariedade? Antes de qualquer outra coisa, uma modalidade contratual que se centre na redistribuição justa, na alocação eqüitativa dos benefícios, dos custos e dos riscos sociais.

Em suma, o que se propõe é um novo concerto institucional e uma nova racionalidade jurídica baseados na idéia de compromisso, de arranjo, de negociação possível entre distintos direitos conflitantes.

Entendido nessa perspectiva, o direito social implica a adoção de uma forma jurídica própria, que se expressa num modo específico de exercício do poder peculiar aos Estados do bem-estar, coexistindo de maneira tensa e problemática com a forma jurídica anterior subjacente ao direito liberal moderno, o que se pode verificar nos seguintes desdobramentos contraditórios:

1. A interpenetração entre esfera pública e esfera privada, sobretudo pelo reconhecimento do caráter público e coletivo de que se revestem demandas tradicionalmente concebidas numa dimensão individual e privatista, tais como as que dizem respeito à saúde, às relações de trabalho, ao consumo, ao meio ambiente e à segurança pública; 
2. A articulação entre racionalidade política e racionalidade jurídica, seja pela própria forma indetermidada que assumem conceitos normativos com caráter social, seja pela entrada em cena de novos atores coletivos no âmbito do sistema de justiça, seja ainda pela reconstrução das pautas hermenêuticas e da própria práxis judicial, delineando aos poucos as bases para a emergência de uma nova cultura de operação e funcionamento da justiça;

3. A tensão progressiva entre racionalidade jurídica formal de procedimentos, própria do liberalismo, e racionalidade jurídica material de fins, própria do Welfare, o que indica a convivência tensa entre os ditames da norma abstrata, genérica e impessoal com a norma programática e de resultados, seja no campo econômico, seja no campo social; da sanção com caráter estritamente punitivo com a sanção de caráter premial; do princípio da igualdade formal com o princípio de justiça corretiva, do instituto da propriedade privada com a sua função social;

4. A contraposição entre os desideratos da certeza do Direito e da segurança jurídica, de um lado, e a ideal de justiça material, de outro, na medida em que o reconhecimento jurídico das contradições sociais pelo Direito implica doses cada vez maiores de incerteza interpretativa das normas, notadamente no que se refere ao conflito de princípios integrantes de um mesmo ordenamento jurídico.

5. O conflito entre os chamados poderes da República, seja pela tendência à hipertrofia do Executivo, que absorve parcela significativa da competência legislativa clássica, pela correspondente fragilização progressiva do Parlamento, seja ainda pela politização crescente do Judiciário.

No âmbito do direito social, dotado dessa racionalidade jurídica teleológica, a função jurisdicional diz respeito não mais apenas ao estabelecimento do lícito e do ilícito a partir da fixação do sentido formal da norma, mas também, e sobretudo, ao exame do exercício discricionário do poder de legislar a partir dos resultados objetivados no marco normativo. No campo da saúde, o controle judicial das atividades do Legislativo e do Executivo tem de se haver cada vez mais com a questão de saber se os objetivos fixados na Constituição estão ou não sendo efetivamente alcançados.

\section{DESCOMPASSO}

Desse ponto de vista da materialidade histórica do direito social, o que parece se verificar hoje no campo da saúde no Brasil é a existência de um tremendo descompasso entre o alcance e o sentido sociais que o sistema jurídico constitucional conferiu à política de saúde, em sintonia com a experiência histórica dos Estados de bem-estar do século XX e com a redemocratização do país na passagem dos anos 70 para os 80 , de um lado, e, de 
outro, o desafio de implementar esse sistema jurídico de saúde numa ordem social cada vez mais travejada por um conjunto bastante abrangente de transformações histórico-sociais vinculadas ao contexto de globalização da economia capitalista.

É exatamente esse hiato que parece alimentar a coexistência contraditória no país de um arranjo jurídico-institucional até certo ponto sofisticado de proteção da saúde e de uma realidade sanitária ainda bastante degradada - na medida em que expressa o desnível que se pode verificar entre a orientação welfarista do texto constitucional, dos princípios que estabelece e da categoria de direito social que consagra, de um lado, e a emergência de uma nova realidade social produzida sobretudo pela marcha da reestruturação capitalista contemporânea, de outro.

Reestruturação capitalista que tem assinalado entre outras mudanças:

1. a passagem do "capitalismo organizado", característico dos anos dourados de estabilização econômica e política, prevalecente nas décadas de 50, 60 e 70, nos países avançados, e das diferentes estratégias desenvolvimentistas adotadas por inúmeros países periféricos, para o "capitalismo desorganizado" dos nossos dias, marcado pela progressiva erosão das políticas intervencionistas keynesianas, pela correspondente revitalização da crença no caráter auto-regulador dos mecanismos de mercado, pela crescente desregulamentação das atividades econômicas, pela flexibilização das estruturas normativas e pela destituição de direitos, notadamente no campo social;

2. a transição do regime "fordista" de acumulação para o novo regime "toyotista", também conhecido como regime da "acumulação flexível" da produção, abrindo o caminho para a empresa-rede e a desintegração, informalização e precarização crescentes do mercado de trabalho, que entreabrem em sentido estrito a chamada nova questão social;

3. a passagem do Estado do bem-estar para o Estado pós-Social, que tem acarretado, entre outras conseqüências:

(a) uma erosão da soberania e da capacidade decisória do Estado Nacional, à medida que inúmeras variáveis econômicas tendem a escapar freqüentemente à possibilidade de controle interno e que a sua pauta tradicional de competências é crescentemente esvaziada pela emergência de novos atores regionais e globais (blocos de integração econômica, conglomerados transnacionais, agências multilaterais, como o Banco Mundial, o Fundo Monetário Internacional e a Organização Mundial do Comércio), no plano supranacional, e pela política de privatizações, no plano infranacional, configurando uma situação de progressiva fragmentação das relações de poder contemporâneas;

(b) um déficit crescente de legitimidade do Estado deflagrado, entre outros fatores, pela desestabilização das finanças públicas, pela guerra 
fiscal, pela deterioração da qualidade da infra-estrutura e dos serviços públicos nos centros urbanos das grandes metrópoles globais, pela contração das políticas públicas, pelo recrudescimento das manifestações nacionalistas, tendo em vista os novos fluxos migratórios entreabertos pela globalização, pelo crescimento da violência e da criminalidade e pelo agravamento do desemprego, da precarização do mercado de trabalho e da polarização social;

(c) uma diminuição da capacidade de resposta do Estado aos conflitos sociais contemporâneos, que decorre, fundamentalmente, do descompasso entre o alcance, o ritmo e a intensidade da integração dos mercados e o alcance, o ritmo e a intensidade da integração dos sistemas político e jurídico, implicando uma dificuldade crescente por parte dos governos para fazer face aos novos desafios globais. Noutras palavras, enquanto os novos conflitos vão assumindo uma dimensão claramente transnacional, os Estados permanecem, em grande medida, adstritos ao exercício da jurisdição dentro dos limites do território nacional.

4. esse conjunto de transformações responde, de modo significativo, pela crise do Direito na sociedade contemporânea, levando mesmo alguns autores a identificarem uma "exaustão paradigmática do Direito Moderno" (Faria, 1999), na medida em que

(a) de um ponto de vista funcional, os mecanismos jurídicos tradicionais tendem a perder eficácia à proporção que se apresentam cada vez maiores dificuldades para a filtragem, a absorção e a regulação competente dos novos conflitos de interesse característicos da sociedade contemporânea;

(b) de um ponto de vista operacional, o sistema jurídico parece crescentemente incapaz de propiciar e garantir um ambiente de segurança jurídica à sociedade, na medida em que a calculabilidade e a previsibilidade das condutas sociais e a certeza das expectativas normativas tendem a esbarrar num contexto econômico altamente volátil e errático;

(c) essa crescente ineficácia dos mecanismos jurídicos tradicionais para regular os novos conflitos de interesse, atrelada ao clima hostil de insegurança jurídica, tende a pôr em xeque a capacidade do Direito em instituir e fazer valer as condições indispensáveis ao próprio acatamento da ordem jurídica, acarretando uma crise de legitimidade do sistema jurídico, o que se pode verificar por exemplo na proliferação de comportamentos tendentes a contornar os mecanismos oficiais de regulação de conflitos por parte dos mais diferentes atores sociais, seja no andar de cima, seja no andar de baixo da sociedade;

(d) de um ponto de vista teórico, pode-se perceber a erosão progressiva do potencial analítico e descritivo de muitas das categorias desenvolvidas 
pelo pensamento jurídico moderno, em especial, nos limites deste trabalho, da própria categoria de direito social a que se vincula o direito à saúde.

É no interior desse gap histórico que se entrechocam crescentemente os princípios constitucionais de proteção da saúde e a hora histórica de sua efetivação num novo contexto de reforma neoliberal do Estado, sobreposição da racionalidade econômica às racionalidades jurídica e sanitária, progressiva vulnerabilidade da vida, gestão desigual de riscos sanitários e privatização dos cuidados da saúde.

O que parece decisivo, hoje, é que, num contexto de crise fiscal e de relativização da soberania do Estado, no qual relações econômicas crescentemente flexíveis tendem a (re)pôr em marcha o "moinho satânico" do movimento tautológico de autovalorização do capital - para empregar a conhecida expressão de Polanyi (1957) - , o fundo público parece cada vez mais unidirecionado para o financiamento das demandas da nova economia, sem a contrapartida welfarista do investimento nas políticas do antivalor, o que parece estar minando uma das condições materiais de possibilidade da proteção jurídica dos direitos sociais, como é o caso justamente do direito à saúde.

Da perspectiva das conseqüências que esse novo contexto traz para o campo das políticas de saúde, veja-se nessa mesma direção o fino comentário de Amélia Cohn e Paulo E. M. Elias,

Diante desse novo desafio - o de pensar as políticas sociais e de saúde na atual conjuntura de uma sociedade fraturada, em que os projetos sociais encontram seus limites no contexto de globalização, e de uma realidade na área da saúde em que o projeto da Reforma Sanitária encontra-se esgotado enquanto formulação de uma proposta concreta - o SUS - acolhida pela nova constitucionalidade, e articulada a um projeto político também já esgotado - a construção da institucionalidade democrática no país -, o que se verifica é o próprio esgotamento das análises, dos estudos e das propostas setoriais formuladas pela mesma comunidade científica autora daquele ideário. (2002:177)

\section{PARADOXOS}

Em linha com esse diagnóstico, é necessário refletir urgentemente sobre o que pode significar formular e executar políticas de saúde num contexto histórico travejado pelos seguintes paradoxos ou curto-circuitos:

1. o Estado regulador da desregulação;

2. a racionalidade privada do fundo público;

3. a afirmação da autonomia do sujeito vulnerável;

4. a social-democracia do encarceramento em massa. 
Salvo engano, paradoxos entreabertos pela atual configuração Ornitorrinco do país, segundo a fórmula original de Francisco de Oliveira: um bicho esquisito, que não é isto nem aquilo, nem desenvolvido, nem tampouco subdesenvolvido, em que a marcha truncada do desenvolvimento em tempos de terceira revolução industrial entreabre um período histórico específico de neoatraso, em que os traços herdados do subdesenvolvimento passam por uma desqualificação suplementar e a exceção se normaliza no dia-a-dia nacional. Numa palavra, o momento é de desagregação, com inequívoco rebatimento na área da saúde.

Do lado da função regulatória do Estado, percebe-se claramente que regulação estatal e neoliberalismo andam de mãos dadas, na medida em que a intervenção pública na economia se dá cada vez mais a partir do imperativo da viabilização e da garantia de novas oportunidades de negócio, especialmente aquelas propiciadas pelo processo de privatização dos serviços públicos. Em análise pioneira, desenvolvida no curso "O nascimento da biopolítica", Foucault descortinou o sentido da regulação jurídica neoliberal, ao notar que ela requer uma institucionalidade que positive o mercado e a racionalidade econômica como lugares de veridicção das práticas governamentais. Noutras palavras, a verdade da intervenção do Estado neoliberal reporta-se à construção das condições que auxiliem na instituição do mercado, da concorrência e da forma-empresa como potências informadoras da sociedade (não custa lembrar a figura contemporânea do Estado gerente). Em termos jurídicos, o risco estaria na passagem da velha polícia estatal de mercado para uma espécie de mercado-polícia de Estado.

Para Foucault, uma das diferenças centrais entre o velho liberalismo e o neoliberalismo residiria precisamente aqui:

Tendo em vista que [para os ordoliberais] o Estado é portador de defeitos intrínsecos, e que nada prova que a economia de mercado tenha esses mesmos defeitos, vamos pedir à economia de mercado que ela própria seja não o princípio de limitação do Estado [velho liberalismo], mas o princípio de regulação interna do Estado, de toda sua existência $e$ ação (...) Em outras palavras: um Estado sob vigilância do mercado em vez de um mercado sob vigilância do Estado. (p. 120)

Ainda nos termos do estudo foucaultiano, as relações entre Estado e mercado se redefinem numa direção precisa, já que não se trata mais de fixar a delimitação recíproca entre esses campos: "não vai haver o jogo do mercado que é preciso deixar livre e, depois, o campo em que o Estado começa a intervir, pois, precisamente, o mercado (...) só pode surgir se for produzido, e ele só é produzido por uma governabilidade ativa." Nessa medida, verifica-se uma espécie de "superposição completa dos mecanismos de mercado indexados sobre a concorrência e a política governamental (...) É preciso governar para o mercado, em vez de governar por causa do mercado" (p. 125). 
Dessa perspectiva, não se trata apenas de preservar as boas, velhas e famigeradas leis de mercado, mas de estendê-las a toda a sociedade, de tal modo que as instituições venham a ser efetivamente essas leis: que elas venham a ser o princípio da regulação econômica geral e, em conseqüência, o princípio da regulação social. Daí por que, nas palavras instigantes do filósofo, "nenhum intervencionismo econômico, ou o mínimo intervencionismo econômico, e o máximo de intervencionismo jurídico" (p. 172).

Um indicador brasileiro dessa zona de tensão no campo da saúde refere-se, no meu modo de ver, à crise de identidade vivida pela Agência Nacional de Saúde Suplementar (ANS) ao tentar compatibilizar regulação do setor privado e viabilização econômica desse mercado, chancelando por exemplo reajustes nos planos de saúde bem acima dos níveis de inflação e aprofundando no país o fosso entre os que podem e os que não podem comprar serviços privados de saúde.

Do lado do fundo público, verifica-se hoje no país que ele não tem propiciado as condições para uma efetiva desmercantilização das relações sociais, função central do Estado de bem-estar e condição de efetividade dos direitos do antivalor, mas, ao contrário, na esteira do processo de financeirização da riqueza, bem como da tradição patrimonialista brasileira, ele tem sido apropriado e gerido para garantir a reprodução financeira do capital e o novo padrão de acumulação rentista.

Importa assinalar quanto o campo das políticas sociais tem sido afetado pela lei de ferro da responsabilidade fiscal, que, entre nós, se desvirtua freqüentemente em política de contigenciamento sistemático de recursos públicos escassos, destinada a lastrear a remuneração de capitais especulativos. Com Márcio Pochmann, notemos o sentido inequívoco do disparate: em 2003, nada menos do que $10 \%$ do PIB anual foi transferido como pagamento de juros ao mercado financeiro, então dominado por cerca de 15 mil famílias!

Segundo os cálculos do economista, os efeitos no campo sanitário já se fazem sentir: se no longínquo ano de 1985, o Brasil registrou a realização de 12,1 milhões de internações hospitalares e a existência de 538,7 mil leitos disponíveis à população, em 2001, já com 13 anos de Constituição cidadã em vigor, os números decaem respectivamente para 11,9 milhões de internações e 485,9 mil leitos disponíveis. Ainda segundo dados do insuspeito Banco Interamericano de Desenvolvimento, no mesmo ano de 2001, o gasto com saúde no Brasil foi de US\$222 por habitante, enquanto na Argentina foi de US\$ 679 e no Uruguai, de US\$ 603 por habitante.

Uma outra dimensão da racionalidade privada que o fundo público assume tem que ver com a própria mudança na percepção do sentido e do alcance das políticas sociais. Como se sabe, no lugar das velhas políticas universalistas de bem-estar entram em cena as famigeradas políticas de 
focalização. A ideologia política e jurídica da inclusão cede o passo à retórica privada da gestão e da eficiência administrativa. Para alguns estudiosos dessa guinada, a opção política por despolitizar o discurso e as práticas governamentais no campo social se evidencia no novo léxico da "cidadania gestionária", ou seja, aquela que se volta não para a identificação e superação das desigualdades sociais, mas para a administração eficiente dos danos considerados inevitáveis do processo econômico. Num contexto de crescente terceirização do governo, o mercado da cidadania e dos projetos sociais se converte ele mesmo em objeto de desejo e consumo: "cidadania: a gente se vê por aqui" (Abilio, 2006).

Sem falar na vantagem comparativa de propiciar a celebração acrítica de uma sociedade civil supostamente mais organizada, assim como de viabilizar o marketing da responsabilidade social das grandes corporações que desempregam a torto e a direito e de difundir a pregação edificante da dignidade da pessoa humana que estende a mão às miríades de consumidores hipossuficientes.

A exumação do Plano de Assistência à Saúde (PAS), sob a égide da atual administração social-democrata de São Paulo, constitui uma bela imagem do que aqui se está designando de "cidadania gestionária".

O terceiro paradoxo se expressa no retorno de uma ideologia de responsabilização individual por riscos coletivos que celebra a autonomia do sujeito no exato momento histórico em que a globalização econômica funda a vulnerabilidade social como norma da sociabilidade. Num tempo em que a neopobreza reassume dimensões dickensianas e a devastação social produzida pelo desemprego, pela informalização e pela precarização generalizada das relações de trabalho impera, eis que ressurge como farsa, da terra arrasada do neodarwinismo social contemporêno, a figura mitológica, a miragem burguesa, jurídica e iluminista do indivíduo plenamente responsável por si próprio.

Responsável, antes de tudo, por gerir em bases individuais e privadas os riscos coletivos advindos da pobreza, da violência, do desemprego e da doença, enfim, da miséria do mundo contemporâneo. Nas palavras de Foucault, o novo homem econômico do neoliberalismo aparece como um "empreendedor de si mesmo, sendo para si mesmo seu próprio capital, sendo para si mesmo seu próprio produtor, sendo para si mesmo a fonte de [seus] rendimentos" (p. 232).

Ou seja, o humano adquire valor de mercado e se apresenta como forma de capital. Nesta nova quadra histórica, "o capital concretiza-se não apenas em dinheiro ou mercadorias, mas em atributos humanos; o capital é investido de formas humanas" (p. 190).

Num cenário de mercantilização quase total da existência, o próprio corpo do indivíduo figura como patrimônio a ser gerido em bases eco- 
nômico-racionais, vale dizer, como qualquer investimento, se sujeita a um cáculo de custos e benefícios em termos de exposição a riscos sociais e sanitários de natureza variada.

Daí a preocupação crescente, como nos trabalhos do sociólogo alemão Thomas Lemke, com o possível advento de uma eugenia de mercado, que além de viabilizar a identificação e o monitoramento de indivíduos percebidos como fonte de risco, com evidente viés social e de classe, sacramenta a possibilidade de aquisição e gestão do patrimônio genético em bases mercantis. Da perspectiva desse contexto distópico, o grau de exposição a agravos sanitários a que está sujeito o indivíduo tende a variar segundo o equipamento genético que o consumidor solvente pode escolher e adquirir.

Quanto ao paradoxo da social-democracia do encarceramento em massa, a atual crise da segurança pública de São Paulo é bastante elucidativa. Em sintonia com o modelo prisional norte-americano e com a construção contemporânea de um Estado Penal, as sucessivas administrações paulistas, ao longo do período de redemocratização, têm reeditado no país, em escala e intensidade absolutamente inéditas, a surrada política do tratamento criminal da questão social e da gestão policial da miséria.

Para consertar um dos piores sistemas carcerários do mundo, prescreve-se a importação do modelo norte-americano do encarceramento em massa, em que estratos populacionais inteiros têm sido aprisionados, no bojo de todo um cortejo de autênticas conquistas civilizatórias: legislação draconiana, instituição de supermax, suspensão de direitos dos presos, recrudescimento da pena de morte e reedição das famigeradas chain gangs com efeitos simbólicos arrasadores. No fundo, como apontam inúmeros analistas, Guantánamo e Abu Ghraib indicam a extensão e a intensificação de práticas punitivas autoritárias hoje bem sedimentadas no berço da democracia moderna.

Dessa perspectiva, o que se verifica hoje no país do futuro é o paradoxo do consumo de modelos ideológicos truculentos de combate à violência cujas dimensões mais regressivas encontram-se profundamente enraizadas em nossa própria sociedade. Ou seja, em matéria penal, corremos o risco de importar modelos de última geração que nunca deixaram de ser coisa nossa.

Medidas como tolerância zero, encarceramento em massa e privatização de presídios constituem a resultante de um tremendo processo de regressão do discurso e das práticas jurídicas penais verificado no contexto dos países do centro, notadamente anglos-saxões, como os Estados Unidos, por assim dizer, na vanguarda do atraso. Essa regressão tem a ver basicamente com a crise do Estado de bem-estar e o esgotamento de seu modelo de segurança pública, ao mesmo tempo que ela também reforça a manutenção e o aprofundamento de um amplo e variado repertório de práticas 
bárbaras de controle do crime, característico da história nacional, e que é reposto nestes tempos de reestruturação capitalista.

Para além do óbvio impacto na saúde pública, seja do ponto de vista do recrudescimento dos crimes violentos praticados dentro e fora dos presídios superdimensionados, influindo de modo decisivo nas taxas de mobimortalidade, seja pela disseminação de doenças infecto-contagiosas que constituem parte da paisagem do nosso sistema penitenciário, seja ainda pelo abandono progressivo de estratégias preventivas de controle da violência, a política brasileira de encarceramento em massa tem propiciado distorções de ordem orçamentária que já se expressam no balanço das contas públicas do Estado.

Com efeito, segundo dados da Secretaria da Fazenda de São Paulo, no ano de 2004, em termos de investimentos na Administração Direta, os gastos do Estado com presídios ficaram em primeiríssimo lugar na rol da execução orçamentária paulista. De um total orçamentário de $R \$ 1,160$ bilhão, as prisões consumiram algo como $\mathrm{R} \$ 237,5$ milhões, ao passo que a saúde, desbancada para o segundo lugar da lista, ficou com R\$ 206 milhões e a educação com R\$ 194 milhões. Note-se que a segurança pública consumiu outros $R \$ 136$ milhões. Ou seja, no ano de 2004, presídios e segurança pública representaram nada mais nada menos do que $32 \%$ de todo o investimento público realizado pelo Estado de São Paulo na Administração Direta.

\section{CONCLUSÕES}

Se tais paradoxos indicam sérias dificuldades e amplos desafios para o futuro da política de saúde no país, quem sabe eles também apontem um caminho possível a ser trilhado por uma ainda incerta e titubeante, porém mais do que necessária, resistência. Especialmente no que cabe à reflexão acadêmica, talvez não seja de todo um mau começo o desarme das armadilhas semânticas que hoje se escondem nos moldes abstratos de expressões como regulação, fundo público, responsabilidade individual, social-democracia, risco e direito social. 